\title{
REVITALISASI PENDIDIKAN AL-ISLAM DAN KEMUHAMMADIYAHAN PADA PERGURUAN MUHAMMADIYAH
}

\author{
Oleh : Zalik Nuryana, S.Pd.I., M.Pd.I \\ Pendidikan Agama Islam Universitas Ahmad Dahlan Yogyakarta \\ Email : zalik.nuryana@pai.uad.ac.id
}

\begin{abstract}
ABSTRAK
Perjalanan bangsa ini tidak lepas dari nama KHA Dahlan yang mendirikan Muhammadiyah. peran besar Muhammadiyah dalam pembangunan bangsa tercermin dalam segala sendi kehidupan bangsa. Fondasi gerakan Muhammadiyah atas telaah Dahlan dalam membaca teks al-Qur'an dan konteks Sosial Kauman saat itu, membawa perubahan besar bagi Indonesia dan Dunia. Jumlah amal usaha bidang pendidikan mencapai ribuan dan tersebar keseluruh pelosok negeri. Capaian ini jelas secara kuantitas sangat membanggakan. Hal ini bisa menjadi tantangan dan peluang. Tantangan untuk meningkatkan kualitas pendidikan Muhammadiyah dan peluang untuk basis perkaderan Muhammadiyah. pendidikan Muhammadiyah memiliki empat fungsi, yaitu: Pertama sebagai sarana pendidikan dan pencerdasan, Kedua, pelayanan masyarakat, dakwah amar ma'ruf nahi munkar dan Keempat, lahan kaderisasi. Misi pendidikan Muhammadiyah tersebut sekaligus menjadi solusi dan respon terhadap keringnya ruh keagamaan dalam pendidikan, Muhammadiyah memiliki ciri khas yaitu pendidikan al-Islam dan Kemuhammadiyahan. Dua hal itu menjadi ciri khas sekaligus solusi dalam mengisi kekeringan ruh spiritual dalam pendidikan, baik pada pendidikan dasar dan menengah maupun pada pendidikan tinggi di Muhammadiyah. Seluruh Amal Usaha Muhammadiyah (AUM) pendidikan harus melaksanakan pendidikan al-Islam dan Kemuhammadiyahan sebagai fondasi pendidikan. AIK yang sudah berjalan pada lembaga Muhammadiyah harus di vitalkan kembali fungsinya. Sehingga empat peran dan misi pendidikan Muhammadiyah dapat berjalan seperti yang di cita-citakan. Revitalisasi AIK didasari oleh realitas yang menganggap kurang begitu pentingnya AIK di pendidikan Muhammadiyah. semangat yang kian melemah itu perlu segera kita respon positif. Revitalissi berarti, pertama, mengadakan AIK bagi yang di perguruan Muhammadiyah belum ada, kedua, memvitalkan kembali fungsi AIK yang sudah berjalan. Dengan mempertimbangkan beberapa aspek. Tujuan pendidikan Muhammadiyah yang dalam grand Desain rencana yang akan mendorong terwujudnya Indonesia yang berkemajuan harus dimulai dengan revitalisasi AIK di perguraun Muhammadiyah.
\end{abstract}

Kata Kunci : Revitalisasi Ismuba, Pendidikan Muhammadiyah, al-Islam Kemuhammadiyahan 


\section{PENDAHULUAN}

Warna pelangi Indonesia tidak bisa terlepas dari salah satu komponen yang bernama Muhammadiyah. Gerakan yang didirikan Ahmad Dahlan pada tahun $1330 \mathrm{H}$ bertepatan pada tahun 1912 M ini membawa dampak besar dalam perkembangan sejarah bangsa ini. Fondasi gerakan Muhammadiyah atas telaah Dahlan dalam membaca teks al-Qur'an dan konteks Sosial Kauman saat itu, membawa perubahan besar bagi Indonesia dan Dunia. Sejarawan taufik Abdullah, dalam beberapa kali pertemuan persiapan muktamar 1 abad di Yogyakarta menegaskan bahwa jasa besar yang disumbangkan Muhammadiyah pada bangsa ini adalah berupa “gerakan mencerdaskan kehidupan bangsa” (Mu'arif, 2012: XII)

Abdul Mu’ti dalam prolog Mengokohkan Spirit Muhammadiyah (Farid dkk, 2010: VII) menegaskan bahwa Muhammadiyah adalah gerakan pembaharuan Islam yang bergerak dalam bidang pendidikan, kesehatan, ekonomi, dan pemberdayaan masyarakat. Pembaharuan dalam bidang pendidikan telah dilakukan Muhammadiyah melalui tiga hal, pertama kurikulum. Pendidikan Muhammadiyah mengajarkan studi agama dan studi umum sekaligus, kedua, pembaharuan metode pembelajaran dari paradigm klasik-modern, ketiga, pembaharuan institusional yaitu perpaduan antara sitem pesantren dan sekolah. Pembaharuan itu tentu akan terus dinamis mengikuti perubahan zaman yang serba cepat.

Muhammadiyah menghiasi sejarah panjang negeri ini. Amal usaha Muhammadiyah dalam bidang pendidikan pada tahun 2000 menurut data dari Pimpinan Pusat Muhammadiyah (2010:XII) memiliki capaian yang luar biasa. Jumlah Sekolah Dasar (SD)/MI 2896, Sekolah Menengah Pertama (SMP)/MTs 1.713, Sekolah Menengah Atas (SMA)/SMK/MA 929, Pondok Pesantren 55, dan Perguruan Tinggi Muhammadiyah 132. Capaian ini meningkat dalam kurun waktu 10 tahun, pada tahun 2010 peningkatan pada jenjang Sekolah Dasar (SD) 2604, Sekolah Menengah Pertama (SMP) 1.722, Sekolah Menengah Atas (SMA) 965, Pondok Pesantren 67, dan Perguruan Tinggi Muhammadiyah 151. Bahkan database Pimpinan Pusat Muhammadiyah dalam website menunjukkan kenaikan dari tahun 2010 sampai sekarang yaitu untuk Sekolah Dasar (SD)/MI 2.604, Sekolah Menengah Pertama (SMP)/MTs 1.772, Sekolah Menengah Atas (SMA)/SMK/MA 1.143, Pondok Pesantren 67, Perguruan Tinggi Muhammadiyah 172. Capaian ini jelas secara kuantitas sangat membanggakan. Melihat data di atas, hal ini bisa menjadi tantangan dan peluang. Tantangan untuk meningkatkan kualitas pendidikan Muhammadiyah dan peluang untuk basis perkaderan.

Sutrisno (2008: 2-3) menjelaskan bahwa dampak berkembangnya dikotomi keilmuan telah melahirkan system Islam yang mandul dan tidak berdaya. Pendidikan Muhammadiyah selalu merespon perkembangan zaman. Kesadaran akan keringnya Islamic value dan dikotomi 
ilmu dalam pendidikan menjadi sorotan Muhammadiyah. Banyaknya amal usaha dalam bidang pendidikan menuntut pembaharuan pendidikan Muhammadiyah yang lebih objektif, dalam arti mampu menyatu dalam kehidupan sosial masyarakat. Mohamad. Ali (2010: XIX) menjelaskan, jika pada tahun 1990an madrasah mengalami modernisasi, pada kurun tersebut sekolah mengalami gejala spiritualisasi. Modernisasi bersifat top-down, sebaliknya spiritualisasi sekolah bersifat bottom-up. Spiritualisasi sekolah dipelopori Pendidikan Muhammadiyah yang menerapkan system pembaharuan dalam pendidikan. Konsep pendidikan Muhammadiyah yang integrative-interkonektif mengajarkan keilmuan Agama dan umum sekaligus, menjadi ciri khas pendidikan Muhammadiyah. Ciri khas ini yang akan menjadi icon pendidikan Muhammadiyah, sekaligus menjadi oase dalam kekeringan ruh spiritual dalam pendidikan.

Dalam Kurikulum ISMUBA Majelis Pendidikan Dasar dan Menengah DIY (Dikdasmen PWM DIY, 2012:II), pendidikan Muhammadiyah memiliki empat fungsi, yaitu: pertama sebagai sarana pendidikan dan pencerdasan, kedua, pelayanan masyarakat, dakwah amar ma'ruf nahi munkar dan keempat, lahan kaderisasi. Dengan adanya fungsi-fungsi tersebut, sekolah dan madrasah Muhammadiyah didesain dan diorientasikan untuk memberikan pelayanan dan peningkatan kualitas lulusan yang unggul dalam kepribadian, keagamaan, keilmuan, keterampilan, berkarya seni-budaya dan berdaya saing tinggi, baik di tingkal lokal, nasional maupun global.Mengacu pada tujuan pendidikan Muhammadiyah yaitu, pendidikan, pelayanan, dakwah, dan perkaderan. Paradigma pendidik dalam lembaga pendidikan Muhammadiyah harus disatukan. Visi-misi pendidikan Muhammadiyah harus di internalisasikan. Paradigma itu membentuk kerangka berfikir dan kesadaran kritis bahwa lembaga pendidikan Muhammadiyah tidak hanya murni pendidikan dan pelayanan, tetapi ada aspek penting lain yaitu misi perkaderan dan dakwah yang menjadi kewajiban masing-masing pendidik di Muhammadiyah untuk melaksanakan misi tersebut.

Misi pendidikan Muhammadiyah tersebut sekaligus menjadi solusi dan respon tentang keringnya ruh keagamaan dalam pendidikan, Muhammadiyah memiliki ciri khas yaitu pendidikan al-Islam dan Kemuhammadiyahan. Dua hal itu menjadi ciri khas sekaligus solusi dalam mengisi kekeringan ruh spiritual dalam pendidikan, baik pada pendidikan dasar dan menengah maupun pada pendidikan tinggi di Muhammadiyah. semua AUM pendidikan harus melaksanakan pendidikan al-Islam dan Kemuhammadiyahan sebagai fondasi pendidikan. AIK yang sudah berjalan pada lembaga Muhammadiyah harus di vitalkan kembali fungsinya. Sehingga empat peran dan misi pendidikan Muhammadiyah dapat berjalan seperti yang di citacitakan. 


\section{ISMUBA/AIK DAN PENDIDIKAN MUHAMMADIYAH}

ISMUBA adalah singkatan dari al-Islam, Kemuhammadiyahan dan Bahasa Arab, sedangkan AIK adalah al-Islam dan Kemuhammadiyahan. Menurut Farid dkk (2010: 30) wawasan pendidikan Muhammadiyah terdiri dari keislaman, kemuhammadiyahan, kebangsaan, keutuhan, dan keunggulan. Wawasan itu merupakan satu kesatuan integral yang patut dikembangkan di setiap lembaga pendidikan Muhammadiyah. Pendidikan Muhammadiyah memerlukan transformasi, tidak cukup hanya inovasi (Zamroni, 2014: 84). Bagian dari tubuh revitalisasi, Pembelajaran AIK yang sudah perjalan di Muhammadiyah perlu ditinjau ulang, dari segi konsep, pelaksanaan, sumber daya, dan komponen pendukung (Organisasi Otonom) yang terintegrasi dalam Grand Desain pendidikan Muhammadiyah.

Tantangan pendidikan Muhammadiyah semakin berat, perubahan pendidikan merupakan sebuah keniscayaan. Muhammadiyah tidak boleh terlena dengan romantisme kuantitas AUM Pendidikan. Pendidikan AIK menjadi ruh pendidikan Muhammadiyah, maka perlu divitalkan fungsinya. Pendidikan Al-Islam diarahkan pada pengenalan, pemahaman dan penghayatan serta pengamalan ajaran Islam yang menekankan keseimbangan, keselarasan, dan keserasian hubungan manusia dengan Allah s.w.t., hubungan manusia dengan sesama manusia, hubungan manusia dengan diri sendiri dan hubungan manusia dengan alam sekitarnya sesuai dengan Al-Qur'an dan As-Sunnah. Pendidikan Kemuhammadiyahan diarahkan pada pemahaman dasar-dasar gerakan dan ideologi Muhammadiyah, seperti tafsir Muqaddimah Anggaran Dasar, Matan Keyakinan dan Cita-cita Hidup ( $\mathrm{MKCH})$, Khittah Perjuangan, Kepribadian Muhammadiyah dan Pedoman Hidup Islami Warga Muhammadiyah, serta pengenalan, pemahaman, penghayatan dan partisipasi aktif peserta didik dalam berbagai gerakan dan kegiatan Muhammadiyah (KTSP Dikdasmen PWM DIY: 4). Dalam pendidikan tinggi kiranya perlu juga diberikan pemahaman tentang Islam Interdisipliner dalam kerangka pendidikan Muhammadiyah, yang diajarkan kepada mahasiswa. Islam Interdisipliner membangun kerangka paradigm Islam dalam masing-masing jurusan. Sehingga semua jurusan diperguruan tinggi punya wawasan yang luas dalam memandang sesuatu.

Pendidikan Muhammadiyah dari tingkat dasar menengah sampai perguruan tinggi harus menjadikan AIK sebagai prioritas khusus. Realitas yang ditemukan, pelajaran yang dianggap sebagai benteng moral dan ideology anak didik di lembaga pendidikan Muhammadiyah dilaksanakan sebatas formalitas (Farid dkk, 2010: 32). Dari kenyataan itulah perlu adanya revitalisasi AIK dalam pendidikan Muhammadiyah dari jenjang dasar sampai perguruan tinggi. 


\section{REVITALISASI ISMUBA/AIK}

Ahmad Dahlan bukan mengembangkan system, akan tetapi mengembangkan etos kerja yang berdasarkan pada prinsip-prinsip ajaran Islam. Ahmad Dahlan bukanlah bermaksud mewariskan "system pendidikan", tetapi mewariskan etos pembaharuan pendidikan. Oleh karena itu yang penting untuk diwarisi adalah etos pembaharuannya, bukan sekedar system pendidikannya (Mohamad Ali, 2010: 10). Etos pembaharuan pendidikan Muhammadiyah seperti yang telah dijelaskan di atas, harus dikawal dan dilaksanakan. AIK merupakan buah dari manisnya pemikiran pembaharuan pendidikan Muhammadiyah. Kalau M. Ali menjelaskan bahwa arah pengembangan pendidikan Muhammadiyah memiliki dua jurusan, yaitu pengembangan fondasional-konseptual dan pengembangan praksis pendidikan yang dilakukan oleh praktisi di lapangan. Maka arah revitalisasi pendidikan Muhammadiyah juga mencakup dua hal itu. Konseptual sebagai fondasi dan pengembangan praktis sebagai implementasi dan penguatan AIK pada perguruan Muhammadiyah.

Pendidikan Muhammadiyah diarahkan menjadi pendidikan Muhammadiyah yang menghidupkan. Pendidikan yang dapat mengatasi permasalahan yang dihadapi ummat manusia. Selama pendidikan tidak diarahkan untuk menghadapi masalah manusia, maka pendidikan itu tidak akan banyak gunanya (Sutrisno, 2008: 52). Revitalisasi AIK diharapkan mampu menjadikan pendidikan Muhammadiyah yang mengidupkan. Dua kerangka dasar dalam penyusunan landasan dan praktis revitalisasi AIK mencakup : Pertama, kesadaran visimisi pendidikan Muhammadiyah, kedua, Penguatan Sumber daya manusia. Banyak faktor yang akan mempengaruhi revitalisasi ini, akan tetapi dalam makalah ini penulis menyampaikan hal yang paling mendasar sebagai fondasi revitalisasi. Berikut uraian singkat masing-masing cakupan:

\section{A. KESADARAN VISI-MISI}

Paradigma pendidikan Muhammadiyah harus dipahami oleh semua kalangan. Empat pilar misi pendidikan Muhammadiyah (pendidikan, pelayanan, dakwah, dan perkaderan) harus benar-benar disosialisasikan sampai ke tingkat paling bawah guru-dosen. Kesadaran ini yang nanti akan membawa kerangka berjuang dalam mencapai tujuan umum pendidikan Muhammadiyah. menurut Zamroni (2014: 136) Perkembangan sekolah sekolah Muhammadiyah secara kuantitas amat menggembirakan, akan tetapi tidak diikuti oleh aspek kualitas yang memadai. Pendidikan Muhammadiyah secara kuantitatif berkembang, akan tetapi secara kulatitas stagnan. 
Tasman Hamami (SM/2016/06/10) menjelaskan bahwa Visi pengembangan pendidikan dasar dan menengah sendiri adalah berkembangnya fungsi pendidikan menengah dengan Al-Islam dan Kemuhammadiyahan sebagai core-nya, Sedangkan, selama ini pembelajaran Al-Islam dan Kemuhammadiyahan di berbagai sekolah Muhammadiyah, masih menghadapi problem, di antaranya pada kurikulumnya, sistem pembelajarannya, serta guru. Selain itu, menurutnya pola pendidikan di sekolah Muhammadiyah khususnya PTM, masih bersifat parsial dan belum secara holistic integrative. Sistem perkaderan utama yang dijalankan dalam bentuk baitul arqom, menurutnya juga belum mampu menjangkau anak didik secara keseluruhan dan luas.

Maka kesadaran dan kesepahaman visi misi pendidikan Muhammadiyah mutlak dilakukan dalam rangka revitalisasi pendidikan Muhammadiyah dari tingkat dasar sampai perguruan tinggi, dari pimpinan sampai pelaksana harian guru-dosen. Kesadaran akan petingnya internalisasi Islamic Value melaui AIK menjadi fondasi revitalisasi. Langkah awal ini harus sukses. Pelaksanaan pendidikan Muhammadiyah di daerah non kota yang menganut system pendidikan apa adanya harus diubah mindset nya. Merubah mindset bukan pekerjaan mudah. Menurut Rhenald Kasali dari pengamatannya manusia suka akan perubahan akan tetapi susah berubah. Perubahan pola dari mental passanger menjadi mental driver (J. Sumardianta, 2013), dalam proses revitalisasi ini tentu juga perlu kesadaran dari semua fihak, terlebih seluruh tenaga pendidik dan kependidikan, bahwa tujuan AUM ditinjau dari segi nama mempunyai makna filosofis yang dalam. Amal adalah manifestasi iman, menjadi spirit perjuangan, dan usaha adalah manifestasi hak. Sehingga lebih menekankan pada spirit berjuang yang dilandasi profesionalitas dengan semangat mental driver. Kesadaran bahwa di lembaga pendidikan Muhammadiyah memiliki tujuan yang tidak hanya sekedar mencari hidup, mencari nafkah, dan mencari kenyaman. Akan tetapi ada tanggung jawab moral dan spiritual dalam mengawal pendidikan al-Islam dan Kemuhammadiyahan.

Munir Mulkhan menjelaskan, cukup banyak "penumpang gelap" yang menikmati hidup dari amal usaha, rapat dari hotel ke hotel dengan menumpang transportasi kelas utama. Ironisnya, kita pun memberikan penghargaan terhadap "penumpang gelap” ini, dan lebih ironis lagi mereka justru dijadikan sebagai seorang "tokoh". Jika persoalan ini tidak segera dipecahkan, maka bukan hanya akan terjadi kelangkaan kader, tetapi amal usaha pendidikan Muhammadiyah juga dapat kehilangan jati diri dan arah. 


\section{B. SUMBER DAYA MANUSIA}

Revitalisasi ISMUBA/AIK akan berjalan sesuai dengan apa yang diharapkan apabila didukung oleh penggerak yang kompeten. Penggerak inilah yang akan mengawal inernalisasi nilai ISMUBA/AIK. Muhammadiyah perlu menyiapkan sumberdaya manusia yang orisinal, orisinal dalam arti mampu memahami konsep pendidikan Muhammadiyah dan mau berjuang untuk mengembangkan pendidikan Muhammadiyah dengan penuh kesadaran. Cara menyiapkan sumber daya yang paling efektif adalah melalui perkaderan. Perkaderan yang efektif bagi Muhammadiyah adalah melalui AUM pendidikannya.

Sumber Daya Manusia (SDM) harus menjadi prioritas Muhammadiyah untuk merevitalisasi system pendidikan Muhammadiyah. Untuk memberikan penjelasan mengenai arah penyiapan sumber daya mari kita lihat

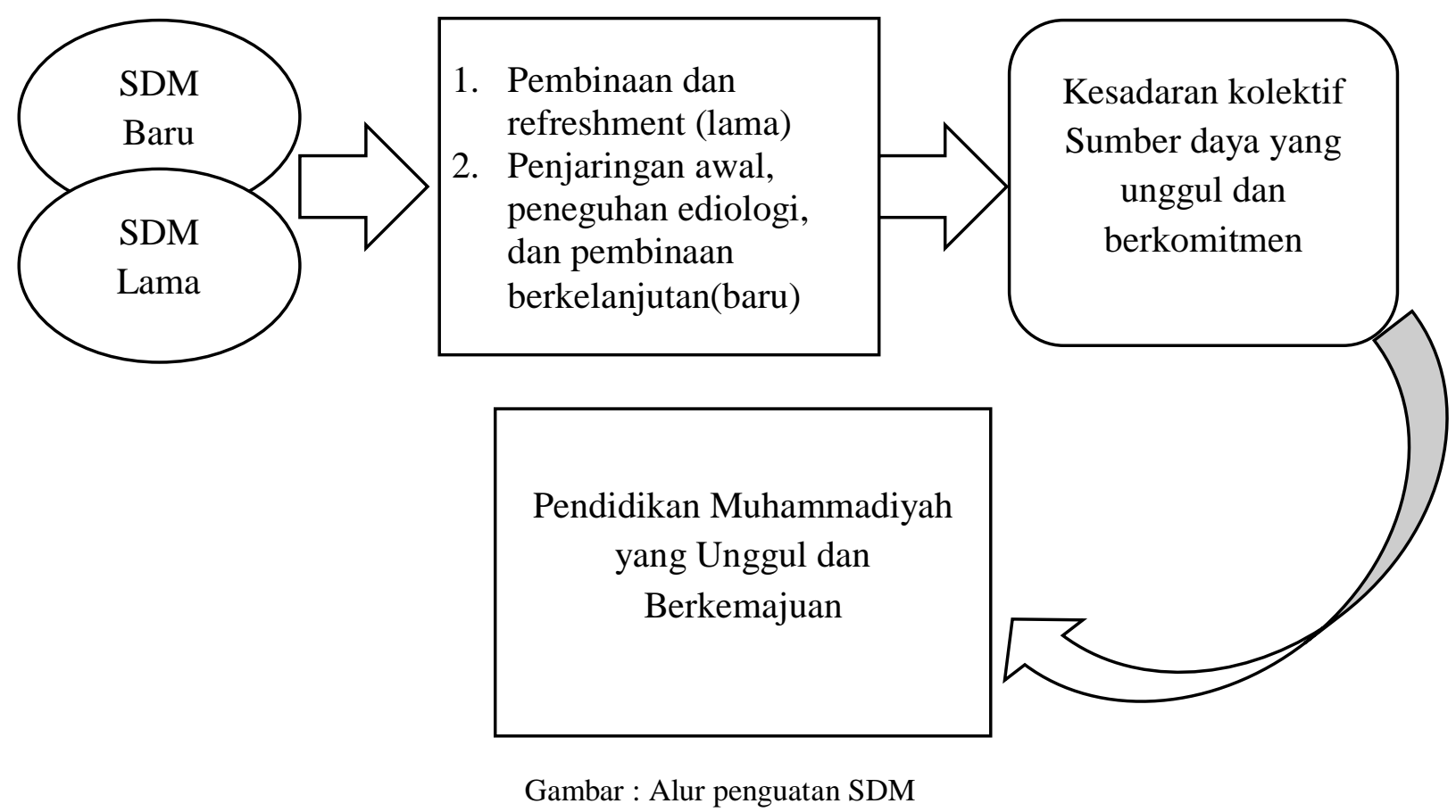

Penguatan SDM melalui dua jalan, Pertama, untuk SDM yang sudah berada di AUM, dilakukan pembinaan dan refresh, baik segi ideology Muhammadiyah maupun tentang ke ilmuan. Kedua, SDM yang baru, dikawal mulai dari recruitment, dilakukan pembinaan dan dikawal, serta penanaman kesadaran bahwa fungsi di Mumammadiyah tidak hanya mengajarkan ke ilmuan tetapi juga internalisasi nilai ke Islaman sesuai dengan faham agama menurut Muhammadiyah. dengan demikian perkaderan dalam tubuh AUM akan berjalan sesuai dengan rel yang sudah ditetapkan untuk mewujudkan pendidikan Muhammadiyah yang berkemajuan. 


\section{PENDIDIKAN MUHAMMADIYAH YANG MENCERAHKAN}

\section{A. REKRUITMEN LEMBAGA}

Memiliki guru/dosen/karyawan yang memahami visi misi Muhammadiyah tentu akan membantu AUM pendidikan dalam mencapai tujuan. Ketika seluruh civitas akademik sudah paham terhadap Muhammadiyah, maka lembaga tingga landas untuk terbang mencapai tujua. Yang menjadi permasalahan adalah ketika orang yang bekerja dalam AUM Muhammadiyah bukan murni orang Muhammadiyah. hal ini tentu menjadi polemik sendiri. Beberapa mengatakan minimnya kader yang menguasai bidang A bidang B dan seterusnya. Padahal ketika kita melihat banyak AUM pendidikan di Indonesia, secara kuantitatif tentu ini hal yang aneh, ketika Muhammadiyah sebesar ini tetapi kekurangan kader, lari kemana para lulusan AUM Muhammadiyah?.

Untuk tetap mengokohkan AUM Muhammadiyah maka perlu dijaring orang-orang yang se visi dengan Muhammadiyah. keberlangsungan AUM pendidikan akan dimulai sejak rekruitmen lembaga. Maka Muhammadiyah berhak membuat syarat dan prosedur serta kriteria orang yang akan bergabung dalam rumah tangga Muhammadiyah. kriteria ini sangat penting dan akan sangat berpengaruh pada gerak langkah AUM pendidikan kedepannya. Orientasi ideologi dilakukan untuk mengawal dan menegaskan arah Muhammadiyah dalam penjaringan guru/dosen/pegawai amal usaha Muhammadiyah agar Muhammadiyah tidak "kecolongan" adanya ideologi lain yang masuk dalam tubuh Muhammadiyah.

Tindakan Muhammadiyah yang terlihat "kaku" atau "tegas" ini akan sangat berdampak pada dinamisasi AUM pendidikan. Pendidikan Muhammadiyah akan menjadi maju dan unggul, karena di dalamnya hanya ada ghiroh perjuangan menuju sekolah maju dan unggul. Tidak ada lagi dosen/guru/karyawan yang tidak sejalan dengan Muhammadiyah, "membicarakan" Muhammadiyah namun tidak mau berubah, dan mempermasalahkan Muhammadiyah. Ketika berbicara ideal tentu banyak pertimbangan dalam fikiran kita yang menganggap bahwa ini berat. Namun sejatinya sikap Muhammadiyah ini yang akan menuntun langkah kedepan. Mulai dari rekruitmen lembaga ini masa depan AUM pendidikan akan ditentukan. Sehingga jalan salah memilih orang yang akan menjadikan AUM pendidikan unggul dan maju.

\section{B. ORIENTASI IDEOLOGI DI AWAL DAN AKHIR PENDIDIKAN}

Revitalisasi pendidikan AIK di perguruan Muhammadiyah di awali dari awal masuk perguruan, baik dari pendidikan dasar sampai pendidikan tinggi. Hal ini dilakukan agar 
nilai ke Muhammadiyah terinternalisasi melalui kegiatan di perguruan Muhammadiyah. sekolah/perguruan perlu ambil bagian dalam mendesain orientasi awal belajar di perguruan Muhammadiyah. Tingkat sekolah, revitalisasi AIK di mulai dari fortasi yang mlibatkan Ikatan Pelajar Muhammadiyah di tinggal ranting/cabang/daerah bahkan wilayah. Kegiatan ini di desain agar nilai AIK bisa menjadi core dalam kegiatan tersebut. Perguruan tinggi dapat melakukan orientasi pengenalan kampus dan menanamkan nilai AIK dalam setiap kegiatan.

Kegiatan ini penulis rekomendasikan dilaksanakan minimal dua kali, di awal masuk dan di akhir sebagai pembelakalan sebelum lulus. Penaman ini tentu harus dikawal betul oleh pimpinan AUM. Semangat revitalisasi AIK harus menjadi kesadaran bersama. Semua elemen harus bahu membahu menanamkan nilai ini. Apabila semua perguruan tinggi Muhammadiyah melakukan hal ini, maka pendidikan Muhammadiyah betul-betul akan menjadi kiblat pendidikan di Indonesia. Semangat KHA Dahlan, yang ingin menjadikan pendidikan Muhammadiyah sebagai pencetak kader ummat dan bangsa ${ }^{1}$ akan tereaisasi untuk menuju masyarakat Indonesia yang berkemajuan melalui jalur pendidikan. Orientasi AIK di perguruan Muhammadiyah tidak boleh di pandang sebelah mata. Mengkader yang terbaik adalah melalui perkaderan itu sendiri.

\section{PERKADERAN DI SEKOLAH}

Mengingat semangat perguruan Muhammadiyah tidak hanya pendidikan saja, akan tetapi pelayanan, dakwah, dan perkaderan, tentu kita tidak boleh menutup mata pendidikan sebagai lahan perkaderan. Untuk itu revitalisasi AIK di perguruan Muhammadiyah harus dimulai dari revitalisasi organisasi otonom di perguruan Muhammadiyah. Tidak bermaksud untuk meniadakan ortom yang lain, akan tetapi di tingkat pendidikan dasar dan menengah perlu dikuatkan lagi minimal tiga ortom di sekolah, Ikatan Pelajar Muhammadiyah, Tapak Suci, dan Hizbul Wathan. Tingkat perguruan tinggi ada Ikatan Mahasiswa Muhammadiyah, Tapak Suci, dan Hizbul Wathan. Semuanya harus menjadi embrio perkaderan di pendidikan Muhammadiyah. penanaman AIK akan berhasil apabila peran ortom di perguruan Muhammadiyah dikuatkan fungsinya. Penjelasan mengenai perkaderan di perguruan tinggi Muhammadiyah, dapat kita lihat sebagai berikut

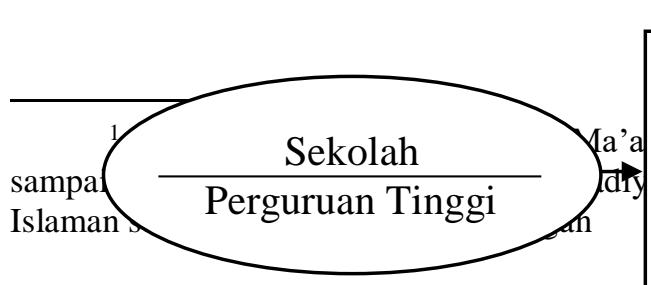

Ada Kurikulum Khusus

AIK/ISMUBA yang diwujudkan dalam mata kuliah/pelajaran ISMUBAKEMUHAMMADIYAHAN

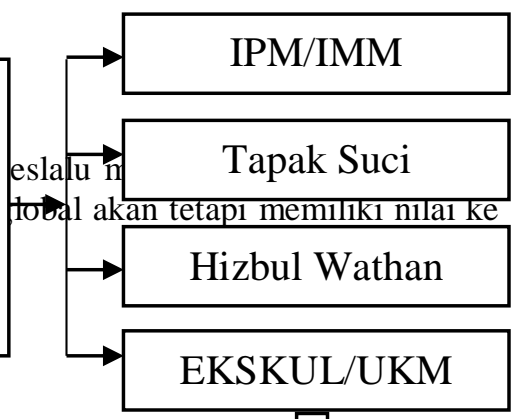


Perguruan Muhammadiyah harus melibatkan ortom dalam proses revitalisasi AIK. Dalam kurikulum AIK harus dimunculkan, tidak hanya menjadi Hidden Curriculum. Dalam pembelajaran formal perlu dimunculkan, kalau dalam pendidikan dasar menengah ada mata pelajaran ISMUBA sebagai core sekolah Muhammadiyah. di perguruan tinggi perlu juga menanamkan nilai AIK dalam kurikulumnya.

Ortom punya peran penting dalam internalisasi nilai AIK. Pemahaman tentang ortom juga harus diketui oleh seluruh lemen pengampu kebijakan di perguruan Muhammadiyah. wajib hukumnya ada dan berlangsungnya ortom sebagai fondasi perkaderan di perguruan Muhammadiyah. dengan adanya kebersamaan ini maka AIK akan menjadi ciri khas perguruan Muhammadiyah, sehingga semakin hari semakin mencerahkan dan berkemajuan, dan tidak akan lekang oleh perubahan zaman yang semakin hari semakin menggilas peradaban. Nilai ke Islaman yang akan mengawal menuju Indonesia berkemajuan, dan salah satu dari proses itu adalah revitalisasi AIK di perguruan Muhammadiyah.

\section{KESIMPULAN}

Muhammadiyah adalah organisi terbesar di Indonesia dengan jumlah amal usaha dalam bidang pendidikan yang banyak. Banyaknya perguraun Muhammadiyah ini menjadi peluang sekaligus tantangan untuk mengelolanya. Pendidikan yang sudah berjalan ini perlu dikuatkan kembali fungsinya. Pendidikan Muhammadiyah memiliki empat dasar semangat yaitu, 
pendidikan, pelayanan, dakwah, dan perkaderan. Empat semangat itu yang tidak boleh padam. Pendidikan sebagai pelayanan dan pendidikan dan juga tidak mengesampingkan fungsi dakwah dan perkaderan.

Revitalisasi AIK didasari oleh realitas yang menganggap kurang begitu pentingnya AIK di pendidikan Muhammadiyah. semangat yang kian melemah itu perlu segera kita respon positif. Revitalissi berarti, pertama, mengadakan AIK bagi yang di perguruan Muhammadiyah belum ada, kedua, memvitalkan kembali fungsi AIK yang sudah berjalan. Dengan mempertimbangkan beberapa aspek. Tujuan pendidikan Muhammadiyah yang dalam grand Desain rencana yang akan mendorong terwujudnya Indonesia yang berkemajuan harus dimulai dengan revitalisasi AIK di perguraun Muhammadiyah.

DAFTAR PUSTAKA

Mohammad Ali. 2009. Menabur Benih Sekolah Unggul di Muhammadiyah, Yogyakarta : Suara Muhammadiyah. 
2010. Reinvensi Pendidikan Muhammadiyah, Jakarta: al-Wasat Publishing House.

Mu'arif. 2012. Modernisasi Pendidikan Islam, Sejarah dan Perkembangan Kweekchool Moehammadijah, Yogyakarta: Suara Muhammadiyah.

Nata, Abudin. 2008. Manajeman Pendidikan, Mengatasi Kelemahan Pendidikan Islam di Indonesia. Cet ke-3, Jakarta: Prenada Media Group.

Rosyadi, Khoiron. 2004. Pendidikan Profetik, Cet. Ke-1, Yogyakarta: Pustaka Pelajar.

Setiawan, Farid, dkk. 2010. Mengokohkan Spirit Pendidikan Muhammadiyah, Yogyakarta: Pyramedia.

Setiawan, Farid. 2015. Geneologi dan Modernisasi Pendidikan Muhammadiyah 1911-1942, Yogyakarta: Semesta Ilmu.

Sutrisno. 2008. Pendidikan Islam yang Menghidupkan, Studi Kritis Terhadap Pemikiran Pendidikan Fazlur Rahman, Yogyakarta: Kota Kembang.

Tafsir, Ahmad. 2005. Ilmu Pendidikan dalam Perspektif Islam. Cet ke-5. Bandung: Remaja Rosdakarya.

Zamroni, 2014. Percikan Pemikiran Pendidikan Muhammadiyah, Yogyakarta: Penerbit Ombak. 